\title{
Silica Aerogel as Super Thermal and Acoustic Insulation Materials
}

\author{
Yanru Lu1 ${ }^{1}$ Xiaodong Li' ${ }^{1}$ Xijiang Yin'1, Handojo Djati Utomo², Neng Fu Tao², Hai Huang1* \\ ${ }^{1}$ Advanced Materials Technology Centre, Singapore Polytechnic, Singapore \\ ${ }^{2}$ School of Architecture \& the Built Environment, Singapore Polytechnic, Singapore \\ Email: ^huang_hai@sp.edu.sg, ‘han@sp.edu.sg
}

How to cite this paper: Lu, Y.R., Li, X.D., Yin, X.J., Utomo, H.D., Tao, N.F. and Huang, H. (2018) Silica Aerogel as Super Thermal and Acoustic Insulation Materials. Journal of Environmental Protection, 9, 295-308.

https://doi.org/10.4236/jep.2018.94020

Received: February 13, 2018

Accepted: April 17, 2018

Published: April 20, 2018

Copyright () 2018 by authors and Scientific Research Publishing Inc. This work is licensed under the Creative Commons Attribution International License (CC BY 4.0).

http://creativecommons.org/licenses/by/4.0/

\begin{abstract}
Silica aerogels are light weight, nanostructured, and highly porous materials with an open pore structure. Due to their excellent characteristics, such as extremely low thermal conductivity, low density and high porosity, the silica aerogels become promising potential adsorbents, catalysts, thermal insulation, and acoustic absorption materials for environmental purposes. This paper presents the synthesis of a highly flexible polymer modified silica aerogel with the use of a cellulose-methyltriethoxysilane (MTES) precursor in a two-step acid-base catalyzed sol-gel process. The physical properties of the resulting aerogels were characterized by thermogravimetry, scanning electron microscopy, nitrogen adsorption-desorption, contact angle, thermal conductivity measurements, compression testing and Fourier transform infrared spectroscopy. The fabricated aerogel exhibited high flexibility with a Young's modulus of compression of $0.33 \mathrm{MPa}$ and the density of $0.132 \mathrm{~g} / \mathrm{cm}^{3}$. They were hydrophobic in nature and had low thermal conductivity. Preparation of aerogel with solid waste (fly ash/bottom ash) is also discussed. The preliminary results showed that the materials have great potential for environmental application, i.e. enhancement of solid waste recycling rate by converting waste to high value-added materials, super thermal and acoustic insulation materials in green building and removal of oil spilled into surface drainage.
\end{abstract}

\section{Keywords}

Silica Aerogels, Polymer Modified, High Flexible, Low Thermal Conductivity, Fly Ash, Bottom Ash, and Environmental Protection

\section{Introduction}

Aerogels are the world's lightest solid materials and have the lowest thermal 
conductivity of solid. As a result of their unique properties, aerogels are being considered for applications as thermal and sound insulation of structural elements in buildings, oil absorbers and catalysts [1] [2] [3].

Silica aerogel is commonly synthesized by either water glass or alkoxides. Samuel Kistler produced the first aerogel by water glass [4], whereas the alkoxides approach is currently more popular because it requires fewer solvent exchanges [5]. The process of aerogel includes two steps: formation of lyogel by water glass or alkoxide and drying (replacement of solvent by air). During the drying process, shrinkage of the gel caused by capillary force in gel pores will lead to a collapse and thereby a failure of aerogel formation [6]. Shrinkage can be eliminated by either supercritical drying or drying at ambient pressure after modification of gel surface [7]. Currently, there are at least four routes to produce aerogels via different gel formations and drying processes.

1) Water glass aerogels by supercritical drying. Samuel Kistler [4] and G. Herrmann [8] explored this approach.

2) Water glass aerogels by ambient pressure drying [9] [10] [11].

3) Alkoxysilane aerogels by supercritical drying [12] [13].

4) Alkoxysilane aerogels by ambient pressure drying [14] [15] [16].

High cost of aerogel production on large scale and the fragility of aerogel have limited its practical applications and commercialization. The high cost of production lies in expensive silica sources, cumbersome solvent exchange process and high energy cost.

In order to reduce the cost of fabrication and realize the commercial production of silica aerogels, green and cheap silica sources are very necessary. Fly ash and bottom ash are industrial wastes released by factories and thermal power plants, which consist of high content of silica. If these wastes could be converted into highly valuable silica aerogels, the environmental pollution problem caused by a stack of fly/bottom ash will be reduced greatly [17]. Horticultural waste (e.g. waste leaves) could be another silica sources with $13 \%-48 \%$ of silica content [18] [19] [20].

Much research has been focused on improving the flexibility and mechanical strength of aerogel. Since aerogel is made up of a network of nano-structured silica chain, its flexibility can be synthetically altered with modification to this network-cross-linking of the silica with organic additives such as cellulose [21], isocyanate [22] [23] [24], methyltriethoxysilane (MTES) [25], and methyltrimethoxysilane (MTMS) [26] have been demonstrated to be effective in enhancing the aerogel's physical properties. Furthermore cellulose, the most abundant organic polymer, may prove to be the key to achieving low-cost aerogel.

This study aims to develop a low cost and high performance aerogel. The paper reported the use of a cellulose-MTES precursor to fabricate hydrophobic aerogel with enhanced physical and thermal insulating properties. Moreover, the study also explored the research on making aerogel from fly ash and bottom ash. An innovative low cost process was developed to prepare ash-based-aerogel. By 
using solid waste as silicon sources, the cost of the aerogel will be reduced significantly.

In 2017, an average of 250 tonnes of incineration fly ash (IFA) and 1350 tonnes of incineration bottom ash (IBA) were generated a day in Singapore's four incineration plants. However, the recycling rate of ash was only $13 \%$ in 2016 [27]. This study provided a new methodology to convert waste to high value-added product and then enhanced the solid waste recycling rate.

\section{Methods and Materials}

\subsection{Polymer Modified Silica Aerogels}

Solvents and catalysts used for the synthesis are methanol ( $\mathrm{MeOH})$, oxalic acid $\left(\mathrm{C}_{2} \mathrm{H}_{2} \mathrm{O}_{4}\right)$, ammonium hydroxide $\left(\mathrm{NH}_{3} \mathrm{OH}\right)$, MTES and ethyl cellulose (Purchased from Sigma Aldrich). $\mathrm{C}_{2} \mathrm{H}_{2} \mathrm{O}_{4}$ and $\mathrm{NH}_{3} \mathrm{OH}$ solutions were further diluted with Deionized (DI) water. Silica Alcosol was prepared by varying the weight ratio of cellulose/MTES from $0.1 \%$ to $0.9 \%$ while keeping the other compositions unchanged. For comparisons, a control sample was also prepared for characterizations.

Firstly, MTES was added after the cellulose was dissolved in methanol solvent with a molar ratio of 19.35. This was then followed with a 5-minute stirring of $\mathrm{C}_{2} \mathrm{H}_{2} \mathrm{O}_{4}$ solution $(0.01 \mathrm{M})$. After about 12 hours, $\mathrm{NH}_{3} \mathrm{OH}(10 \mathrm{M})$ solution was added drop by drop while stirring. The prepared solution was poured into syringes for gelation for 12 hours. Samples were transferred into centrifuge tubes and soaked in $\mathrm{MeOH}$ to exchange the water inside for at least 4 days and methanol should change every day. Lastly, supercritical point dryer was used for drying the aerogel samples. The chamber was filled with liquid $\mathrm{CO}_{2}$ for 4 hours before heating.

\subsection{Aerogels from Fly Ash and Bottom Ash}

Woodchip and coal fly ash/bottom ash samples were received from Sembcorp Industries. The water glass solution was produced by 4 steps. Firstly, the fly ash and bottom ash were leached with $\mathrm{HCl}$ to remove the metal element, e.g. Fe. Secondly, the solution would be removed by filtering the mixture. Thirdly, $\mathrm{NaOH}$ solution reacts with the fly ash and bottom ash to extract the Si. Finally, the water glass solution was obtained by filtering out the fly ash and bottom ash. The synthesis of aerogels was started with the gelation of water glass under different $\mathrm{pH}$ values by using different modes. The hydrogels have to be soaked in DI water to remove salts. DI water was replaced after every 4 hours. The salt-free gels were then aged in absolute ethanol for 24 hours before being left in the solvent mixers of ethanol, hexane and TCMS with a volume ratio of 1:1:1 for 24 hours to reduce the shrinkage and make the alcogel silylated. Finally, the silylated gels will be dried under ambient pressure (Figure 1 and Figure 2).

Large size aerogel blanket with glass fiber was prepared by ash based aerogel. The hydrogels were poured onto 3 layers of glass fiber cottons with the $\mathrm{pH}$ value 


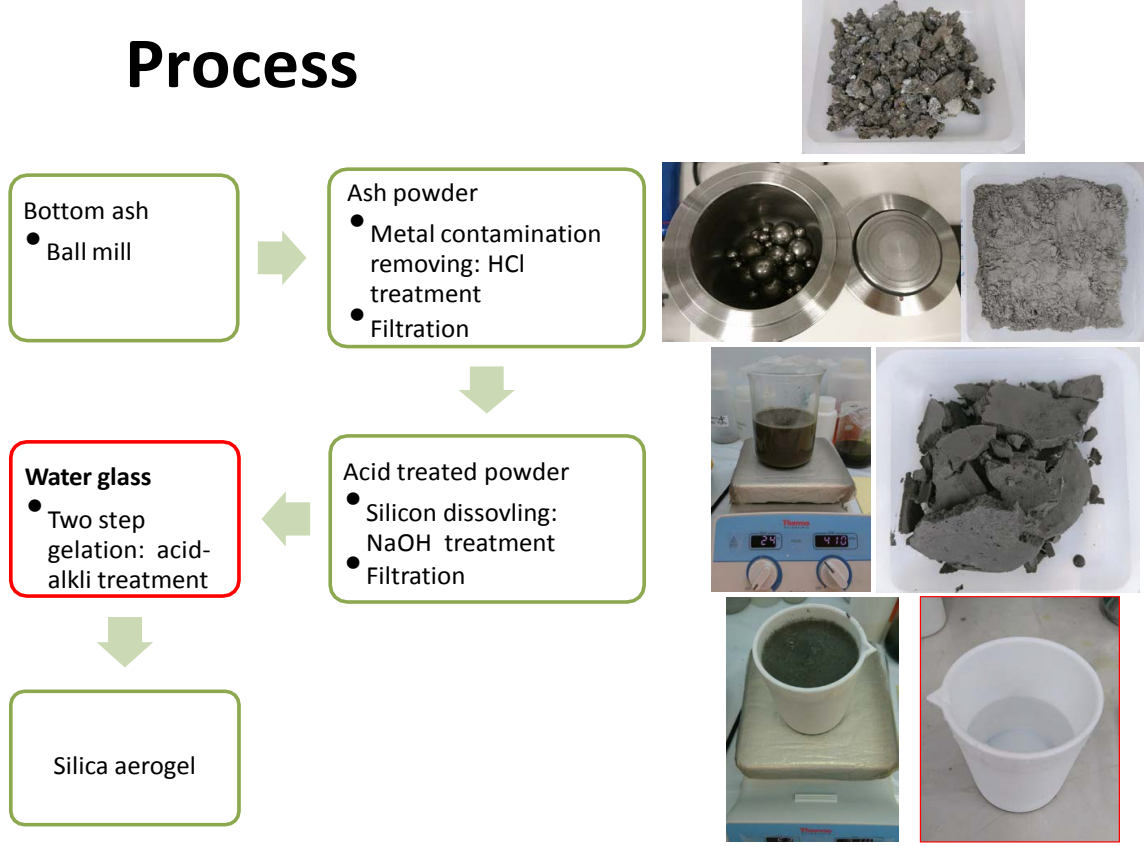

Figure 1. Process of aerogel prepared with fly ash and bottom ash.

\section{Aerogel product \\ Thermal conductivity: $0.05 \mathrm{~W} / \mathrm{mk}$}

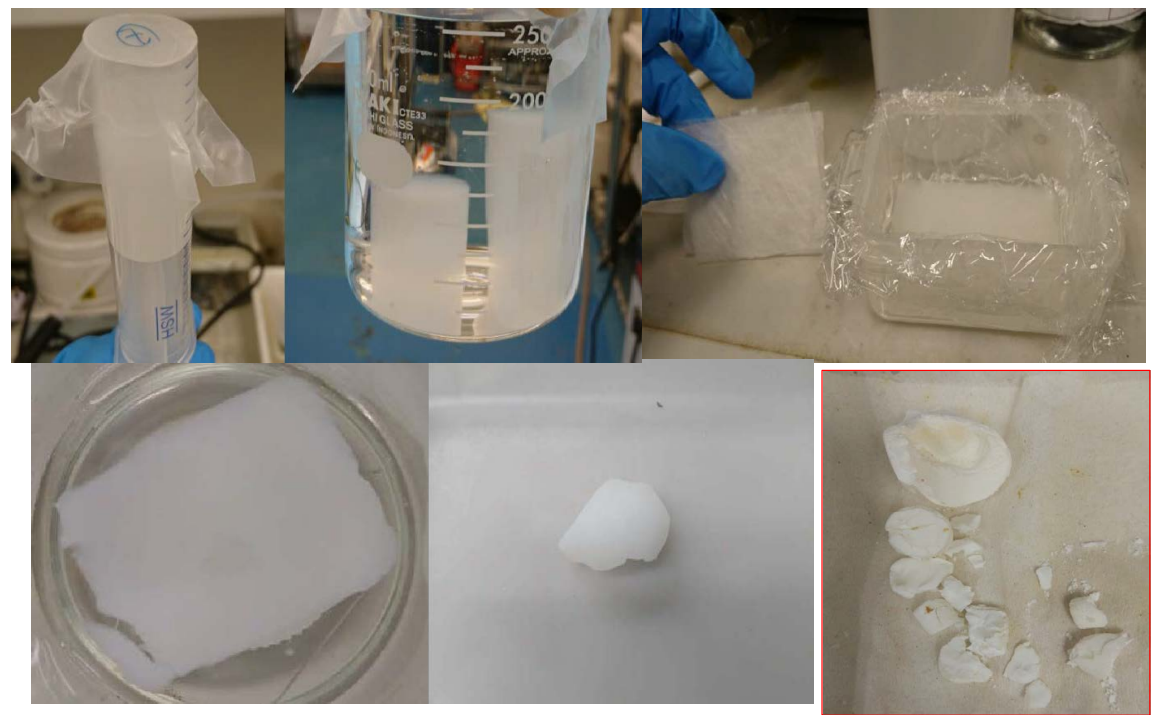

Figure 2. Aerogel product made by fly ash and bottom ash.

of 10.5. After drying, the aerogel blanket was characterized by sound insulation test (Figure 3 and Figure 4).

\subsection{Characterization}

The morphology of the aerogel samples was investigated using a field-emission scanning electron microscopy (FE-SEM, JSM-7001F, JEOL, Japan). The samples 

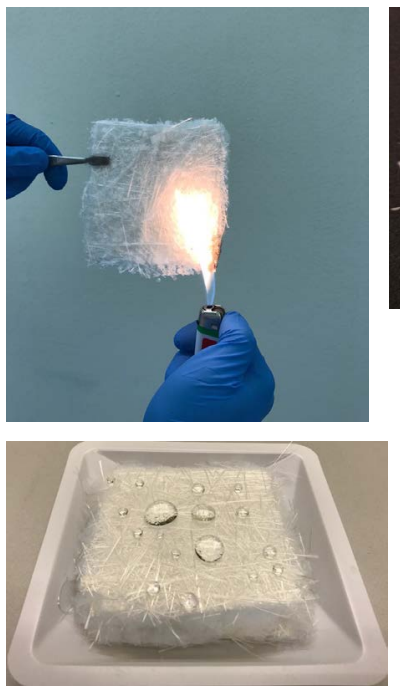
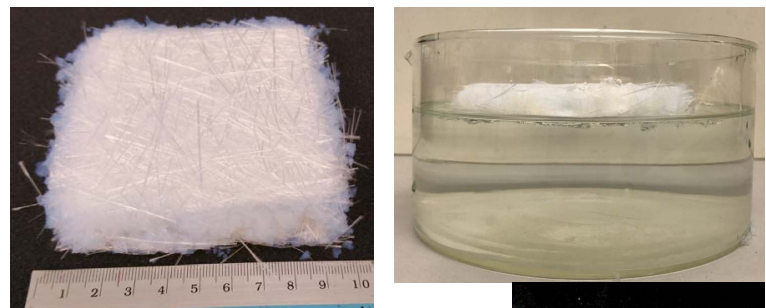

Large size aerogel blanket with superior properties.

Fire proof.

Water proof.

Light weight.

Breathable.

Density: $0.2 \mathrm{~g} / \mathrm{cm}^{3}$

Thermal conductivity: $0.032 \mathrm{~W} / \mathrm{mK}$

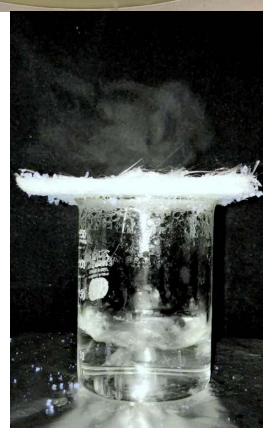

Figure 3. Large size aerogel blanket preparation.

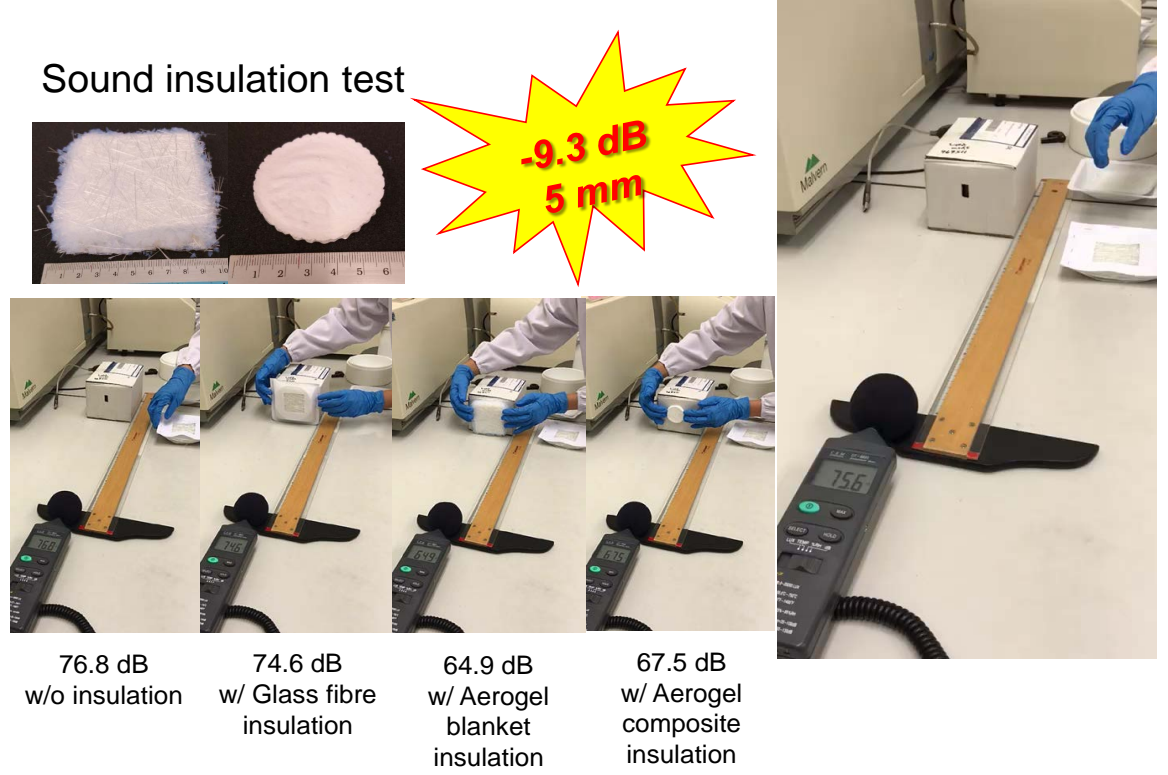

Figure 4. Sound insulation test of aerogel blanket.

were coated with a thin layer of gold by sputtering prior to FE-SEM. The surface area of the silica aerogels and silica cellulose composite aerogels were determined by nitrogen physisorption measurements with a Nova 2200e (Quantachrome, USA). All the samples were degassed in vacuum at $80^{\circ} \mathrm{C}$ for $24 \mathrm{~h}$ before measurement. Hydrophobicity of the aerogels was investigated by conducting a water contact angle test on the aerogels. An automatic contact angle meter (Analytical Technologies Pte Ltd, Singapore) was used to conduct this test. The program was controlled by software built in function where water is dispensed from the syringe at $0.5 \mu \mathrm{l}$ every time. The software then helped to calculate the water contact angle automatically. The measurement was repeated at different positions of the sample and an average was taken. The thermal conductivity of 
the aerogel was determined by a C-ThermTCi Thermal Conductivity Analyzer (C-Therm Technologies, Canada) using the modified transient plane source method under ambient conditions. The TGA (thermal gravimetric analysis) tests were performed by a TGA/DSC Simultaneous Thermal Analyzer (Mettler Toledo, Switzerland) to study the thermal stability of the aerogels. The specimen was heated from room temperature to $900^{\circ} \mathrm{C}$ at a rate of $10^{\circ} \mathrm{C} / \mathrm{min}$ in argon. The structure of the complexes in aerogel composite was studied using a Fourier transform infrared spectrophotometer (FTIR, IRAffinity-1S, Shimadzu, Japan). The compressive test was carried out on a Universal tester (AGS-X, Shimadzu, Japan) to investigate the compressive moduli of the aerogels. During the test, the specimen was under a loading at a rate of $1 \mathrm{~mm} / \mathrm{min}$.

\section{Results and Discussion}

Addition of cellulose was found to enhance the flexibility of aerogel as well as the mechanical strength. Figure 5(a) and Figure 5(b) show the relationship between the weight ratio of cellulose/MTES and the elasticity and density of the fabricated aerogels respectively. From Figure 5(a), it can be observed that the Young's modulus reduces significantly with the addition of very low concentration of cellulose. However, as shown by the increment in the density of aerogel sample in Figure 5(b), increasing the cellulose concentration to above $0.9 \mathrm{wt} \%$ adversely affects the porosity of the nanostructure of the aerogel. This is consistent with the surface area correlation (Calculated from the nitrogen adsorption isotherms that are shown in appendix) with porosity reported [28] for cellulose whereby higher concentrations of cellulose result in lower porosity and hence higher density.

Furthermore, based on the pore size distribution (Figure 5(c)), the pore sizes within the aerogel range from 3 to $30 \mathrm{~nm}$. Notably, it can be observed that addition of a very small concentration of cellulose results in the formation of many small pores. However, the pores did not only reduce but also become smaller when the concentration of cellulose was increased to $1.68 \mathrm{wt} \%$. As such, aside from improving the physical property, addition of cellulose is demonstrated to play the pivotal role of controlling the porosity of the cellulose-MTES aerogel. And this manoeuvrability can prove to be very useful to controlling the thermal insulating property of aerogel.

Since the correlation between the density of the nanostructure of the aerogel and the solid thermal conductivity has been well established [5] [29], increasing the cellulose concentration to above $0.9 \mathrm{wt} \%$ will thus increase the net thermal conductivity considering the preponderance of the solid thermal conductivity to the net thermal conductivity at ambient temperature. Thus the concentration of cellulose has to be fixed at below $0.9 \mathrm{wt} \%$ to prevent any significant reduction in porosity that may degrade the thermal insulating property of the aerogel.

Aside from the addition of cellulose, other compounds used in the fabricating process may also have significant effects on the properties of aerogel. As such, 


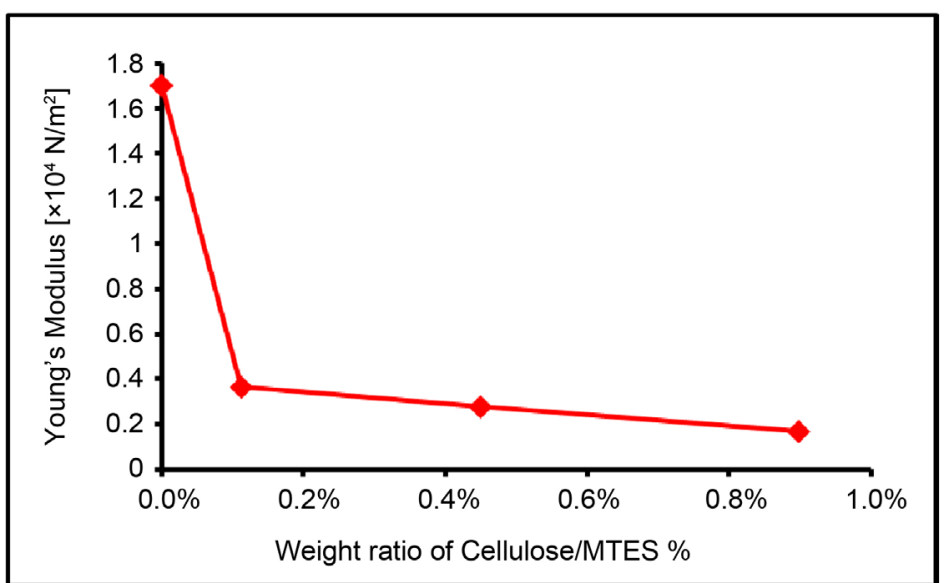

(a)

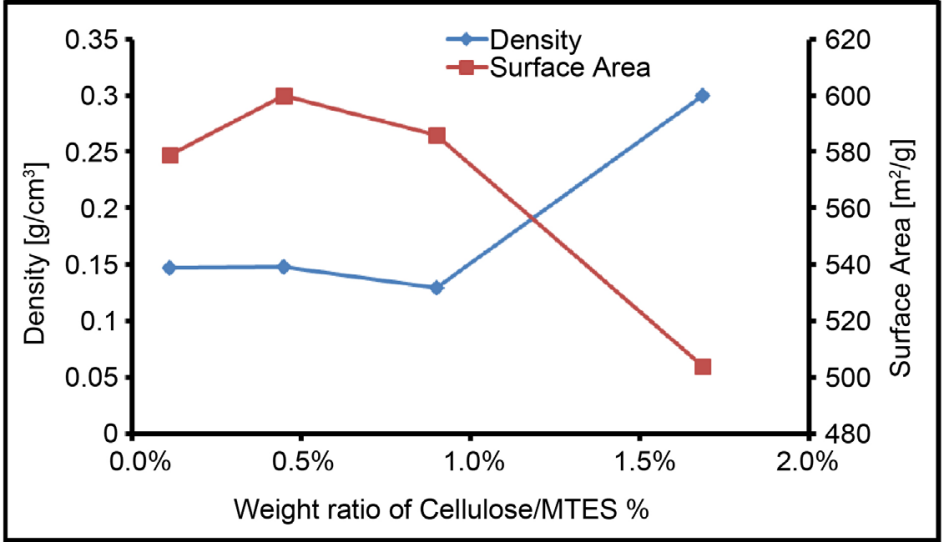

(b)

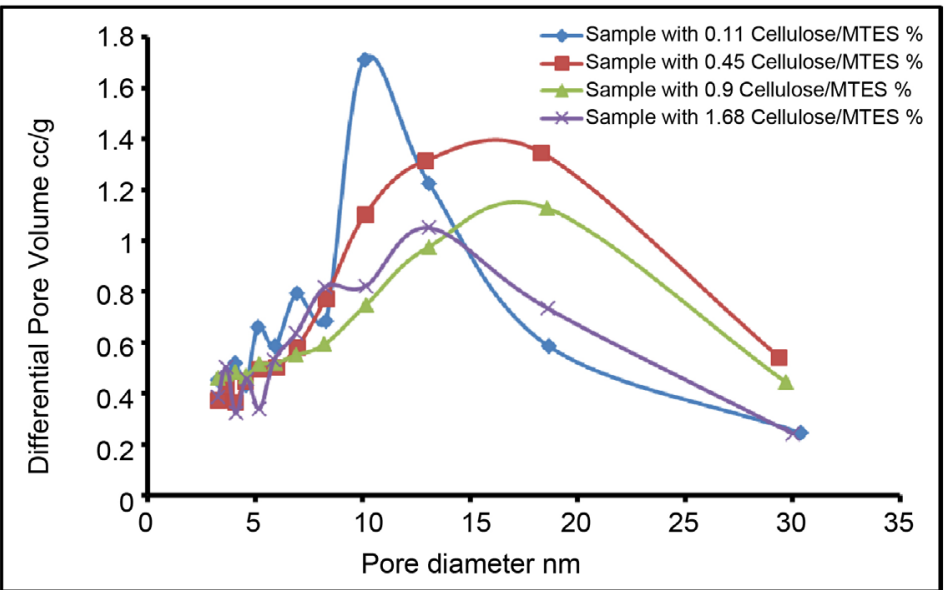

(c)

Figure 5. (a) Characterization of the elasticity of aerogel samples with varying concentrations of cellulose; (b) Characterization of the density and surface area of aerogel samples with varying concentrations of cellulose; (c) Estimated Pore size distributions of cellulose-MTES aerogel samples with varying cellulose-to-MTES concentrations. The above values were calculated from the $\mathrm{BJH}$ model based on their respective nitrogen desorption isotherms. The nitrogen desorption isotherms are shown in the appendix. 
the concentrations of methanol, acid and ammonia catalysts were optimized to achieve the highest elasticity. By comparing the elasticity of the aerogel samples at varying molar ratios of $\mathrm{MeOH} / \mathrm{MTES}$ (Figure 6), it can be concluded that smaller molar ratios of $\mathrm{MeOH} / \mathrm{MTES}$ are desired as the Young's modulus of the aerogel sample was observed to be inversely related to the molar ratio of $\mathrm{MeOH} / \mathrm{MTES}$. On the other hand, increasing the concentration of $\mathrm{NH}_{3} \mathrm{H}_{2} \mathrm{O}$ leads to the decrement of the concentration of MTES, and thus gives rise to larger volume and lower density (Figure 7). However, at molar ratios above 3.6, the rate of polycondensation becomes undesirably fast, leaving behind $-\mathrm{OH}$ bonds after gelation which undergo dehydration polymerization [14] during the aging and drying process. As such, this leads to a higher contraction percentage that explains the observed smaller volume and higher density.

The importance of the aerogel's flexibility to its application in building structures stems from the need for aerogel to be capable of assimilating the different

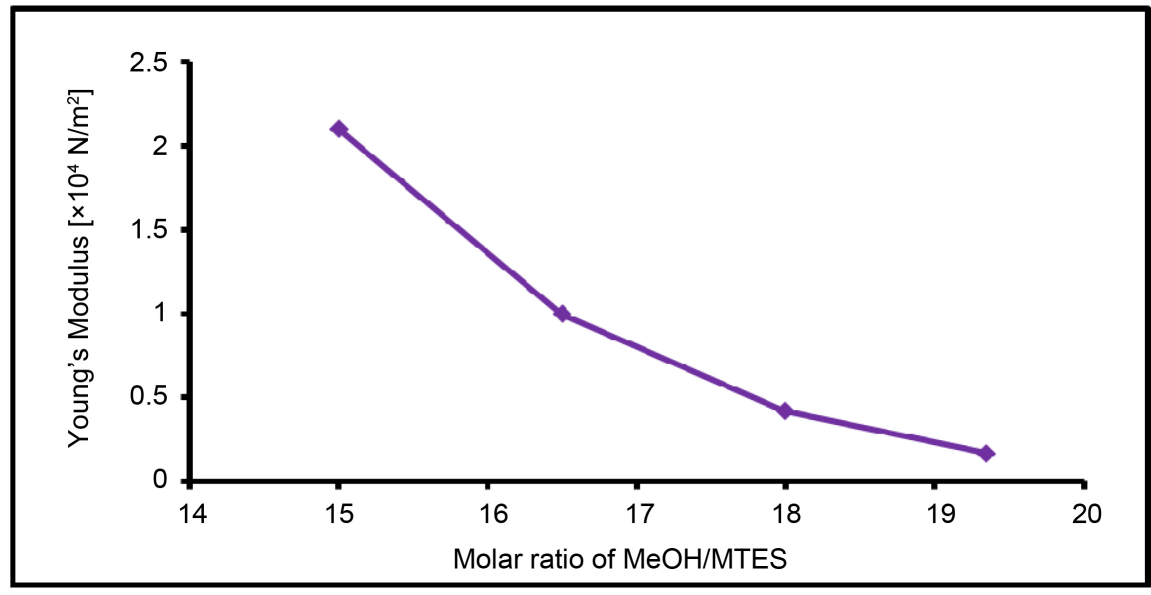

Figure 6. Characterization of the elasticity of aerogel samples with varying molar ratios of $\mathrm{MeOH} / \mathrm{MTES}$. A test sample with molar ratio of 10 (not included in the figure) has a comparatively large Young's modulus that classifies it to be not flexible.

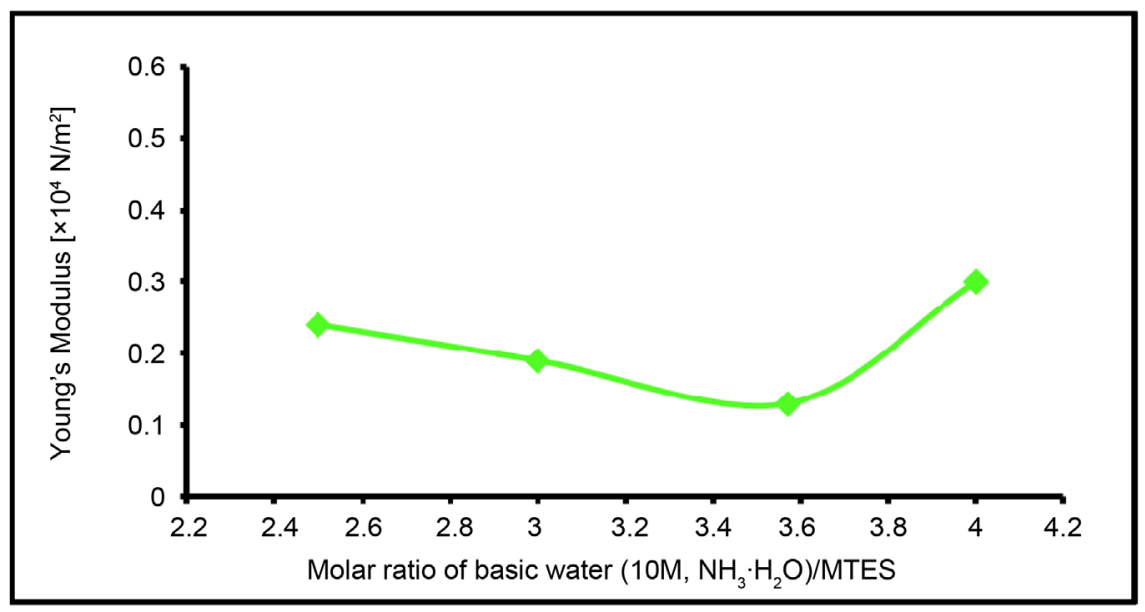

Figure 7. Characterization of the density of aerogel samples with varying molar ratios of $\mathrm{NH}_{3} \mathrm{H}_{2} \mathrm{O} / \mathrm{MTES}$. 
shapes that are becoming increasingly common in modern building architecture. Hence, having aerogel that can be bent or moulded to varying shapes will be valuable to its success in the commercial market. The mechanical strength and flexibility of aerogel samples synthesized from the optimized parameters were demonstrated by simply applying pressure to it (Figure 8). And this enhanced mechanical strength and flexibility can be attributed to the increased porosity of the aerogel caused by the enhanced regularity of spaces and improved connectivity and uniformity of the nanostructure for aerogel samples with cellulose added observed from the high resolution images captured by the Scanning Electron Microscope (SEM) shown in Figure 9(a) and Figure 9(b). And this observation is consistent with the estimated pore distribution illustrated in Figure 5(c). This is in sharp contrast to the captured SEM images for the aerogel sample without cellulose added where the nanostructure and spaces were observed to be highly non-uniform in size and distribution (Figure 9(c)).

As the biggest selling point of aerogel as material for green building is its low thermal conductivity, introduction of cellulose not only enhances the aerogel's flexibility but more importantly reduces its thermal conductivity as well. Given the prevalence of sensors and algorithms in household appliances, lower thermal conductivity will reduce the electricity used both for cooling and warming the interiors of the building during summer and winter seasons respectively. This reduced thermal conductivity can be similarly attributed to the effect of enhanced network with uniformly distributed spaces introduced by the cellulose content. However, the correlation observed between the flexibility and the thermal conductivity of the cellulose-based aerogel as illustrated in Figure 10 corroborates with earlier report that thermal conductivity at room temperature does not depend solely on the density of the nanostructure but can be artificially controlled through other means [30].

Another important property of aerogel is its thermal stability that renders it useful for high temperature applications. Being incombustible makes aerogel a natural shield against fire that can be used as a natural barrier for first-hand

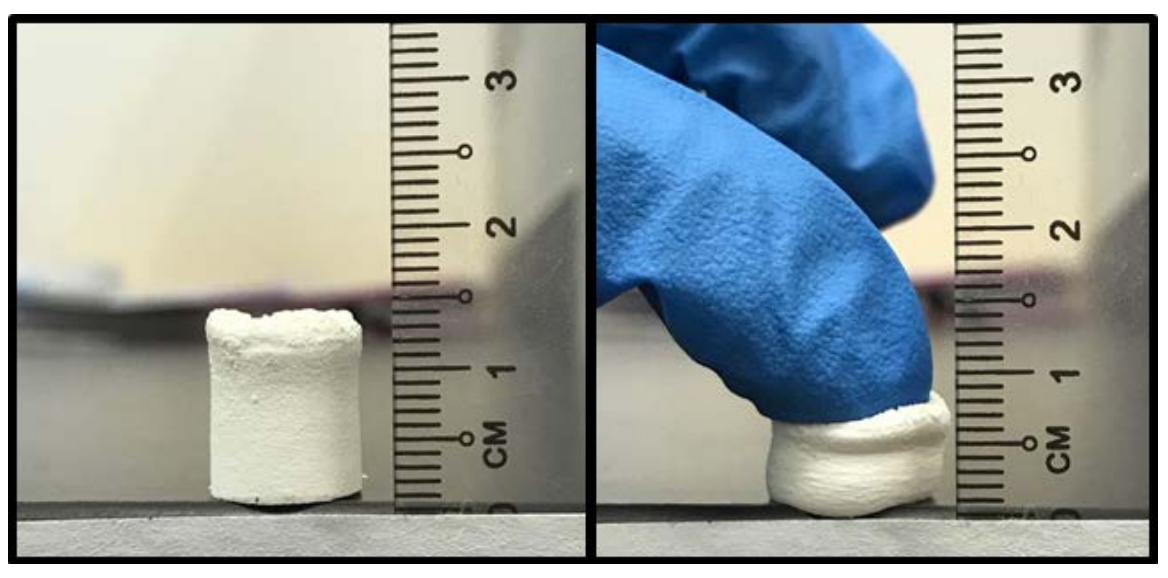

Figure 8. A significant difference in the height before and after applying pressure was observed without any breakage. 


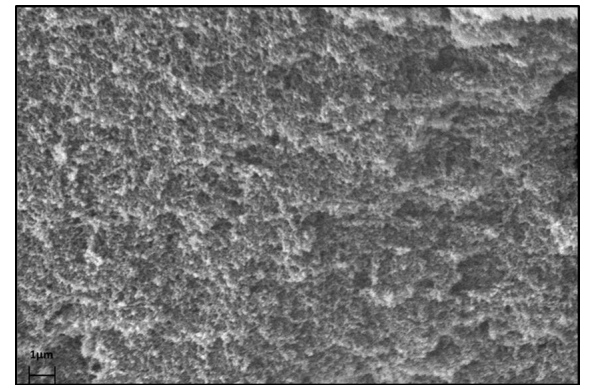

(a)

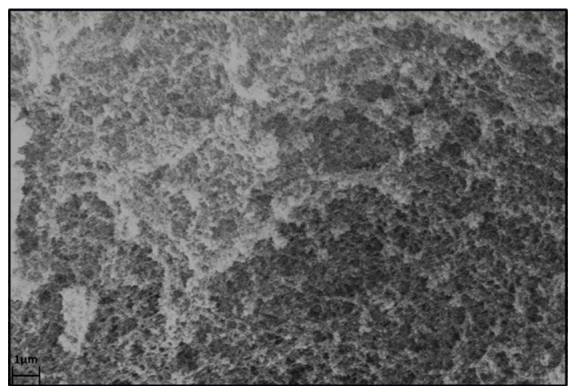

(b)

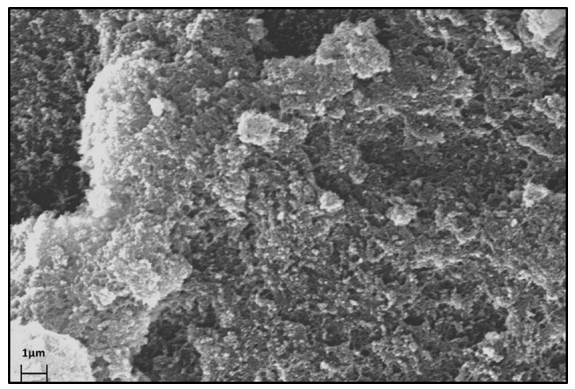

(c)

Figure 9. SEM images of aerogel sample (a) with $0.45 \mathrm{wt} \%$ cellulose/MTES; (b) $0.9 \mathrm{wt} \%$ cellulose/MTES and (c) without cellulose.

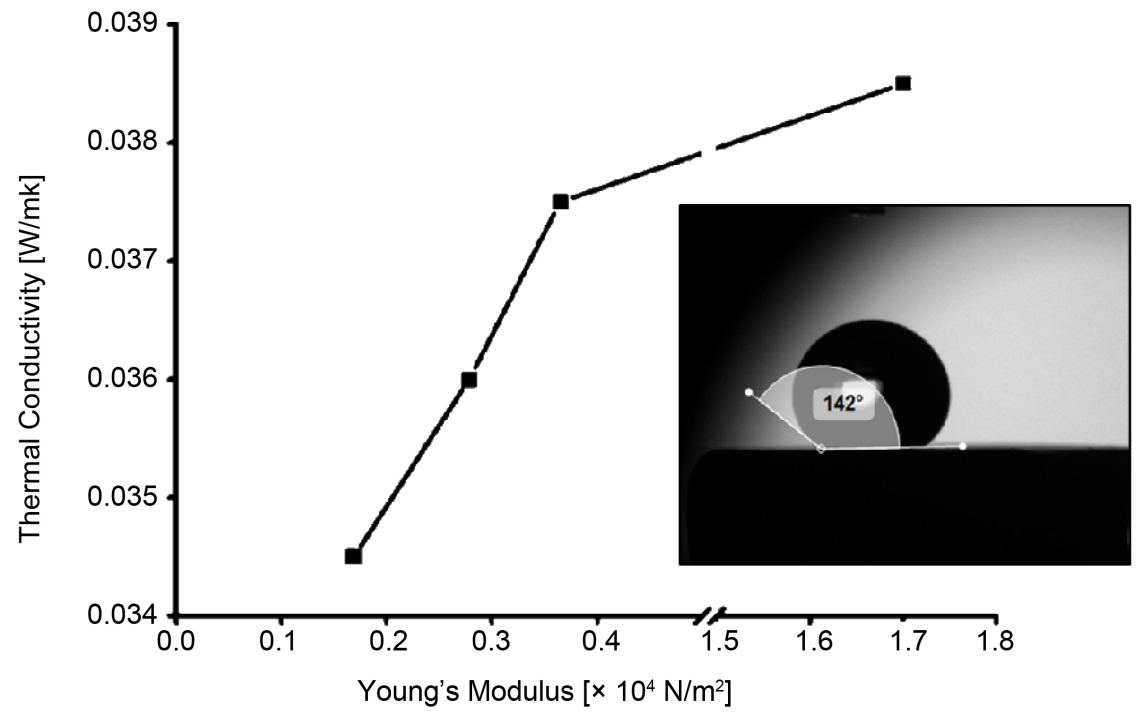

Figure 10. Plot of Thermal conductivity versus Young's modulus for cellulose-based aerogel samples. (Inset) The contact angle of water with an optimized cellulose/MTES-based aerogel was measured to be $142^{\circ}$.

quarantine or isolation of the fire in the event of a fire outbreak. As such, practical integration of aerogel into the building structures is an extremely attractive fire counter-measure for both residential and commercial buildings. However, the cellulose/MTES-based aerogel fabricated exhibited poorer thermal stability as compared to one without as illustrated by the thermogravimetric analysis in Figure 11. Notably, at temperatures beyond $800^{\circ} \mathrm{C}$, the sample with $0.9 \mathrm{wt} \%$ of 


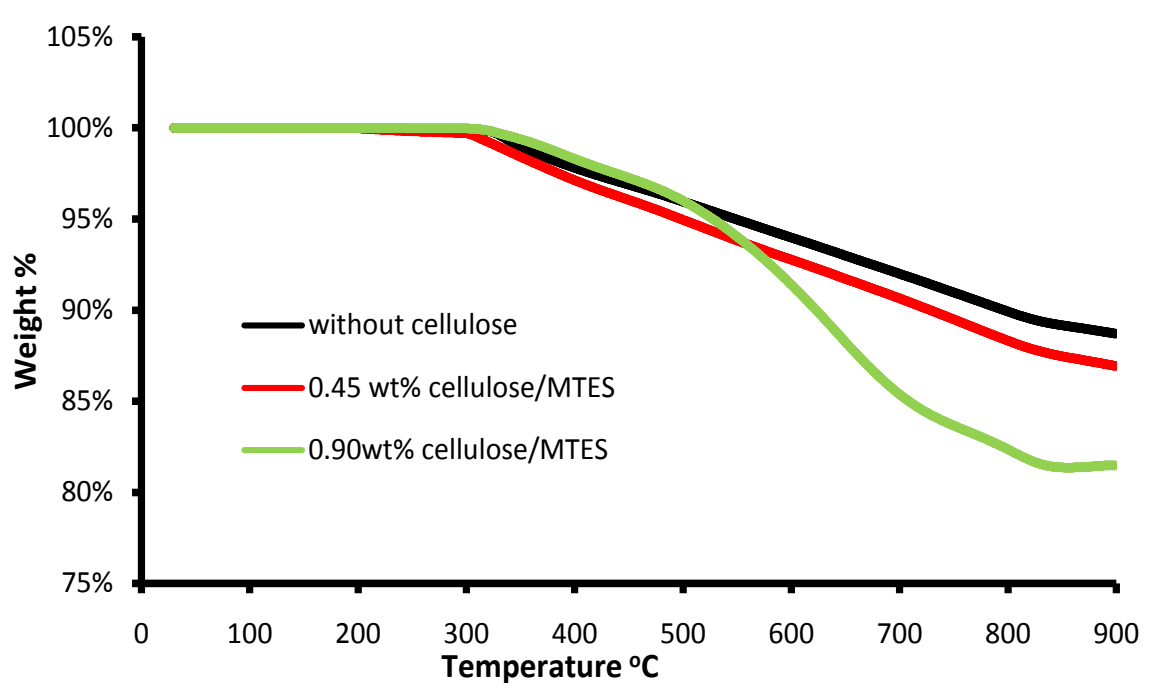

Figure 11. Thermogravimetric analysis was conducted for aerogel samples without cellulose (black), $0.45 \mathrm{wt} \%$ cellulose/MTES (red), and $0.9 \mathrm{wt} \%$ cellulose/MTES (green) up to $900^{\circ} \mathrm{C}$. Weight loss was observed across all samples from $300^{\circ} \mathrm{C}$ onwards. Weight loss was mainly attributed to $\mathrm{Si}-\mathrm{OH}, \mathrm{Si}-\mathrm{CH}_{3}$ and cellulose. Overall, the samples are thermally stable at high temperatures.

cellulose/MTES concentration had lost about $20 \%$ of its weight whereas the sample without cellulose added had lost only $10 \%$ of its weight. And this increased weight loss can be largely attributed to the presence of cellulose in the aerogel that can be determined by the spectral differences in their Fourier Transform Infrared Spectroscopy (FTIR) transmission spectra (Figure 12). Hence, lower concentration of cellulose is favoured for aerogel applications under high temperature.

\section{Conclusions}

MeOH-MTES-based aerogels, the effect of cellulose on the density of the aerogel was found to be negligible so long as the weight percentage (wt\%) is smaller or equal than $0.9 \%$. Additionally, the aerogel fabricated was found to be not only more flexible but also less thermally conductive, thus demonstrating that optimizing both properties simultaneously is feasible by enhancing the porosity while strengthening the nanostructure. Such superior properties are attainable with the addition of $0.9 \mathrm{wt} \%$ of cellulose/MTES after the concentrations of methanol, oxalic acid and ammonia catalysts have been optimized for aerogel synthesis. As such, aside from having lightweight and incombustible properties, hydrophobic aerogel shows promise for applications in Green Building Materials where it is able to provide multiple functionalities for enhancing both sustainability and energy efficiency. Ashes based aerogel and large size aerogel blanket were successfully prepared and exhibited low thermal conductivity and excellent noise insulation property.

The aerogel can be further developed into different forms which enable the implementation of environmental protection. 


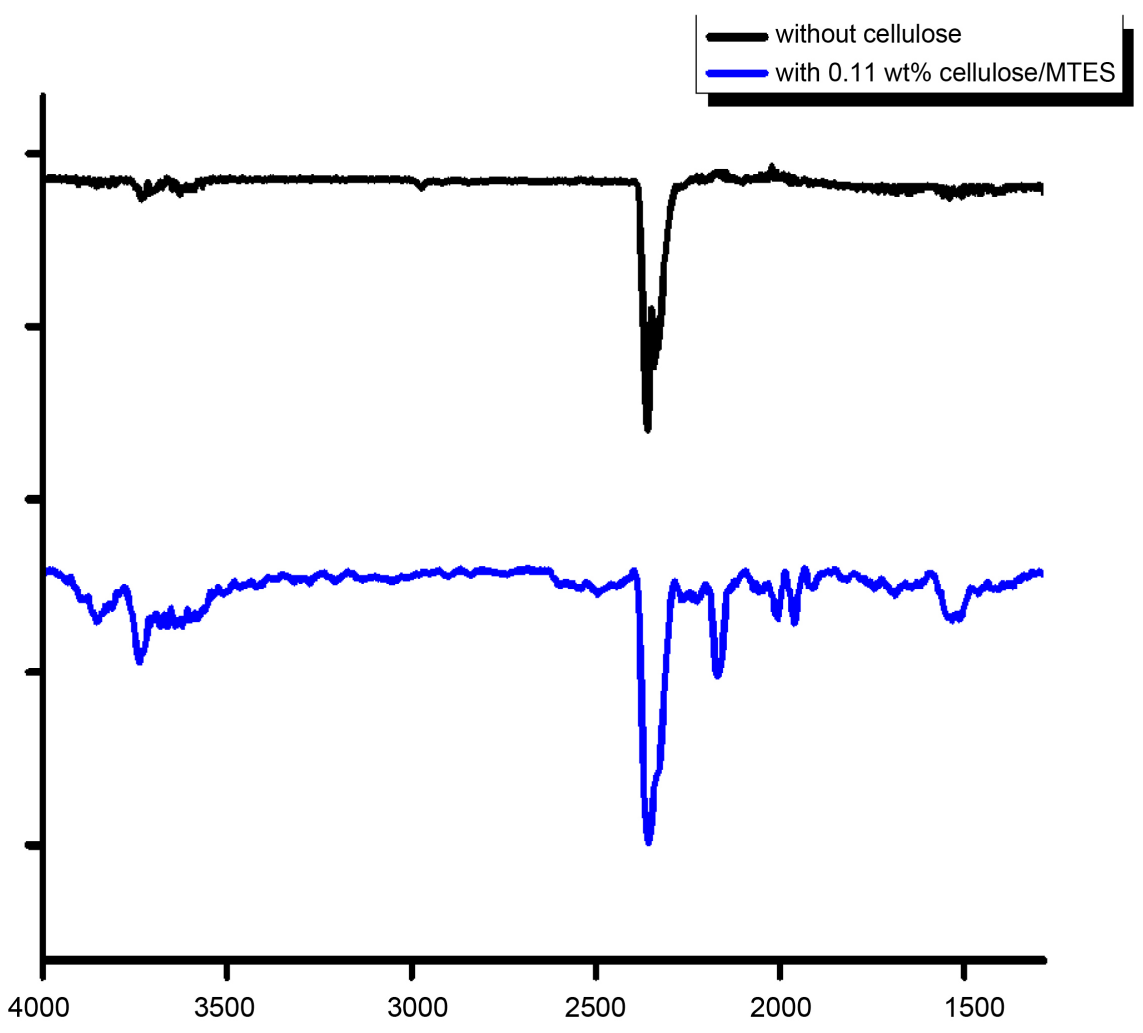

Figure 12. Fourier transform infrared spectroscopy (FTIR) Transmission spectra of aerogel sample without cellulose (black) and with $0.11 \mathrm{wt} \%$ cellulose (blue). The 3 circles highlight the spectral difference that is attributed to the cellulose presence.

\section{1) Aerogel films}

Transparent super hydrophobic silica aerogel film will be deposited on the glass substrate by using spin coating, dip coating, spray coating and screen printing methods. Finally, the solvent will be removed by using ambient pressure drying. The films can be used on windows as thermal and acoustic insulators.

2) Aerogel granulate/powder

Granular/powder silica aerogels will be coated with a hydrophilic layer to achieve better workability and binding with paint, cement and mineral materials in the plaster and rendering system [31]. The hydrophilic coating including $\mathrm{TiO}_{2}$ coating, $\mathrm{Al}_{2} \mathrm{O}_{3}$ coating, polymer coating and so on. The coated aerogel will then be used as additive to prepare paint, plaster and rendering system.

3) Aerogel blanket

The application of the aerogel blanket will be in insulation of walls, roofs, doors and floors. The mechanical strong and flexible aerogel blanket can also be used in membrane filtration system to remove oil from wastewater.

\section{Acknowledgements}

The project was supported by Singapore Polytechnic TIEFA Fund Vote Number 11-27801-36-R162 \& 11-27801-36-R231, ABE \& AMTC's Departmental funds and Sembcorp Industries Ltd. 


\section{References}

[1] Fricke, J. and Emmerling, A. (1992) Aerogels-Preparation, Properties, Applications. Structure and Bonding, 77, 37. https://doi.org/10.1007/BFb0036965

[2] Hrubesh, L.W. (1990) Aerogels: The World's Lightest Solids. Chemistry \& Industry, 17,824 .

[3] Hüsing, N. and Schubert, U. (1998) Aerogels-Airy Materials: Chemistry, Structure, and Properties. Angewandte Chemie International Edition, 37, 22. https://doi.org/10.1002/(SICI)1521-3773(19980202)37:1/2<22::AID-ANIE22>3.0.C O;2-I

[4] Kistler, S.S. (1931) Coherent Expanded Aerogels and Jellies. Nature, 127, 741. https://doi.org/10.1038/127741a0

[5] Dorcheh, A.S. and Abbasi, M.H. (2008) Silica Aerogel; Synthesis, Properties and Characterization. Journal of Materials Processing Technology, 199, 10-26.

[6] Brinker, C.J. and Scherer, G.W. (1990) The Physics and Chemistry of Sol-Gel Processing. In: Brinker, C.J. and Scherer, G.W., Eds., Sol-Gel Science, Academic Press, New York.

[7] Schwertfeger, F. (1998) Innovative Heat Insulation with Aerogels. In: Future Special Science 2, Hoechst Magazine.

[8] Herrmann, G., Iden, R. and Mielke, M. (1995) On the Way to Commercial Production of Silica Aerogel. Journal of Non-Crystalline Solids, 186, 380.

https://doi.org/10.1016/0022-3093(95)90076-4

[9] Tyler, L.J. (1959) Improvements in or Relating to Silica Compositions. Dow Corning, GB 682574.

[10] Tyler, L.J. (1962) Silica Powders. Dow Corning, US 3015645.

[11] Jansen, M. and Zimmermann, A. (1997) Process for the Preparation of Xerogels. Hoechst, US 5647962.

[12] Nicolaon, G.A. and Teichner, S.J. (1968) Étude thermodynamique de l'adsorption d'argon et d'azote par les aérogels de silice. The Journal of Chemical Physics, 65, 1480. https://doi.org/10.1051/jcp/1968651480

[13] Teichner, S.J. (1972) Method of Preparing Inorganic Aerogels. US 3672833.

[14] Davis, P.J., Brinker, C.J. and Smith, D.M. (1992) Pore Structure Evolution in Silica Gel during Aging/Drying I. Temporal and Thermal Aging. Journal of Non-Crystalline Solids, 142, 189. https://doi.org/10.1016/S0022-3093(05)80025-0

[15] Davis, P.J., Brinker, C.J., Smith, D.M. and Assink, R.A. (1992) Pore Structure Evolution in Silica Gel during Aging/Drying II. Effect of Pore Fluids. Journal of Non-Crystalline Solids, 142, 197. https://doi.org/10.1016/S0022-3093(05)80026-2

[16] Deshpande, R., Hua, D.W., Smith, D.M. and Brinker, C.J. (1992) Pore Structure Evolution in Silica Gel during Aging/Drying. III. Effects of Surface Tension. Journal of Non-Crystalline Solids, 144, 32-34. https://doi.org/10.1016/S0022-3093(05)80380-1

[17] Inada, M., Tsujimotoa, H., Eguchi, Y., Enomoto, N. and Hojo, J. (2005) Microwave-Assisted Zeolite Synthesis from Coal Fly Ash in Hydrothermal Process. Fuel, 84, 1482-1486. https://doi.org/10.1016/j.fuel.2004.08.012

[18] Motomura, H., Mita, N. and Suzuki, M. (2002) Silica Accumulation in Long-Lived Leaves of Sasa veitchii (Carrière) Rehder (Poaceae-Bambusoideae). Annals of Botany, 90, 149-152. https://doi.org/10.1093/aob/mcf148

[19] Lux, A., Luxova, M., Abe, J., Morita, S. and Inanaga, S. (2003) Silicification of Bam- 
boo (Phyllostachys heterocycla Mitf.) Root and Leaf. Plant Soil, 255, 85-91. https://doi.org/10.1023/A:1026157424794

[20] Reynolds, J.G., Coronado, P.R. and Hrubesh, L.W. (2001) Hydrophobic Aerogels for Oil-Spill Cleanup? Intrinsic Absorbing Properties. Energy Sources, 23, 831-843. https://doi.org/10.1080/00908310152125210

[21] Tan, C., Fung, B., Newman, J. and Vu, C. (2001) Organic Aerogels with Very High Impact Strength. Advanced Materials, 13, 644-646.

[22] Leventis, N., Sotiriou-Leventis, C., Zhang, G. and Rawashdeh, A. (2002) Nanoengineering Strong Silica Aerogels. Nano Letters, 2, 957-960.

https://doi.org/10.1021/nl025690e

[23] Capadona, L., Meador, M., Alunni, A., Fabrizio, E., Vassilaras, P. and Leventis, N. (2006) Flexible, Low-Density Polymer Crosslinked Silica Aerogels. Polymer, 47, 5754-5761. https://doi.org/10.1016/j.polymer.2006.05.073

[24] Katti, A., Shimpi, N., Roy, S., Lu, H., Fabrizio, E., Dass, A., Capadona, L. and Leventis, N. (2006) Chemical, Physical, and Mechanical Characterization of Isocyanate Cross-Linked Amine-Modified Silica Aerogels. Chemistry of Materials, 18, 285-296. https://doi.org/10.1021/cm0513841

[25] Nadargi, D., Latthe, S., Hirashima, H. and Rao, A. (2009) Studies on Rheological Properties of Methyltriethoxysilane (MTES) Based Flexible Superhydrophobic Silica Aerogels. Microporous and Mesoporous Materials, 117, 617-626. https://doi.org/10.1016/j.micromeso.2008.08.025

[26] Venkateswara Rao, A., Bhagat, S., Hirashima, H. and Pajonk, G. (2006) Synthesis of Flexible Silica Aerogels using Methyltrime-Thoxysilane (MTMS) Precursor. Journal of Colloid and Interface Science, 300, 279-285. https://doi.org/10.1016/j.jcis.2006.03.044

[27] Website of National Environment Agency, Singapore, 2017.

[28] Cai, J., Kimura, S., Wada, M., Kuga, S. and Zhang, L. (2008) Cellulose Aerogels from Aqueous Alkali Hydroxide-Urea Solution. ChemSusChem, 1, 149-154. https://doi.org/10.1002/cssc.200700039

[29] Lu, X., Caps, R., Fricke, J., Alviso, C. and Pekala, R. (1995) Correlation between Structure and Thermal Conductivity of Organic Aerogels. Journal of Non-Crystalline Solids, 188, 226-234. https://doi.org/10.1016/0022-3093(95)00191-3

[30] Meador, M., Capadona, L., McCorkle, L., Papadopoulos, D. and Leventis, N. (2007) Structure-Property Relationships in Porous 3D Nanostructures as a Function of Preparation Conditions: Isocyanate Cross-Linked Silica Aerogels. Chemistry of Materials, 19, 2247-2260. https://doi.org/10.1021/cm070102p

[31] Gao, T., Jelle, B.P., Gustavsen, A. and Jacobsen, S. (2014) Aerogel-Incorporated Concrete: An Experimental Study. Construction and Building Materials, 52, 130-136. https://doi.org/10.1016/j.conbuildmat.2013.10.100 